Conclusions Results from the research project are being used to both prepare an evidence-informed template for IPV intervention for police in New Brunswick and improve training for police officers.

\section{THE PREVALENCE OF INTIMATE PARTNER VIOLENCE AGAINST WOMEN}

Pyae Phyo Zaw, Aung thein Htay, Thit Lwin. Department of Orthopaedics and Trauma, University of Medicine, Yangon.

\subsection{6/injuryprev-2016-042156.983}

Background Women experienced violence in many different forms. It may be physical, sexual, psychological, economical, social and cultural abuse but most commonly is the combination of these. Studies have shown that the rate of intimate partner violence (IPV) against women is still a public health problem. It has both physical and psychological consequences to the victim.

Description of the problem This study as conducted with the aim of determining the prevalence, background characteristics of women and perpetrators and severity of injury.

This was a hospital based cross sectional descriptive study among 6914 women, above 15 years of age attended to the ER, Yangon General Hospital. 134 women who were due to intimate partner violence were interviewed by trained persons using a structured questionnaire.

Results The findings showed the rate of IPV against women is $1.94 \%$ and occurred commonly in young aged of 21-30 years. Alcohol use of male partner was significantly associated with violence. The nature of physical injuries ranged from minor injuries such as abrasions or bruises to major conditions as fractures and internal organ injury. Women with low education and socioeconomic status were more commonly to be committed by their intimate partners.

Conclusion The findings indicate that prevalence of IPV against women is increasing and commonly occurred in young age. The majority of women who experienced IPV have low socioeconomic and education status. There is strong correlation of IPV with alcohol usage of male partner. Prevention of IPV against women should be an urgent public health priority. There should be policies and laws which limits people from alcohol abuse. Health policy makers should plan for possible interventions on prevention of intimate partner violence including provision of education. Health care providers need to be sensitised to the issues of intimate partner violence in order to recognise and treat early.

\section{EXPERIENCE OF INTIMATE PARTNER VIOLENCE AMONG UNIVERSITY LEVEL FEMALE STUDENTS IN KATHMANDU}

${ }^{1}$ Bhagabati Sedain, ${ }^{2}$ Puspa Raj Pant, ${ }^{3}$ Prapti Sedai. ${ }^{1}$ Tribhuvan University, Kathmandu, Nepal; ${ }^{2}$ University of the West of England, Bristol, UK; ${ }^{3}$ Kathmandu University, Kavre, Nepal

\subsection{6/injuryprev-2016-042156.984}

Background Intimate partner violence (IPV) is considered as a private matter, remains hidden and only partly reported in Nepal. Secondary data shows that IPV is increasing in Nepal. Family members and husband are the most common perpetrators for IPV. Available literature indicates the situation is worse among females with poor socio-economic status and lower literacy. No separate evidence of the situation among educated females is available. This study explored violence experienced by university female students and its association with background variables.

Methods This is a cross-sectional survey of female students conducted in 2014 under MENTOR-VIP. The survey questionnaire comprised of 7 sections adopted from WHO's Women's Health Study tools. 500 students (total 2,300) were sampled and 370 were interviewed. Among them 123 were married. Logistic regression was applied to assess the association of independent variables on intimate partner violence. Ethical approval was obtained from the Research Division of Tribhuvan University.

Results Prevalence of intimate partner violence was high (33\%); married students also experienced physical violence. Married students who have land ownership, employed, member of community groups and higher level of husband's education were less likely to experience physical violence. Married students who do not have own land $(\mathrm{OR}=2.92)$, not employed $(\mathrm{OR}=1.21)$ were more likely to experience violence than those having own land and employed. Similarly, lower level of husband's education $(\mathrm{OR}=3.35)$ and unskilled jobs $(\mathrm{OR}=1.56)$ were associated to higher occurrence of violence compared to university level of education and white collar job or working abroad.

Conclusions This study found that intimate partner violence also exists among Nepalese females in higher education. The results provided diverse understandings of lifetime experience of intimate partner violence and would contribute to design intervention and future research agenda in this regard.

\section{WHAT DOES LIBERALISATION AND EMPOWERMENT OF WOMEN HAVE TO DO WITH MALE VICTIMISATION?}

George Darko, Ingrida Grigaityte. Åbo Akademi University, Vaasa, Finland

\subsection{6/injuryprev-2016-042156.985}

Background Previous studies on gender differences in aggression focused on physical aspects of the behaviour, and often showed males more aggressive than their female counterparts. This though, does not mean women are non-aggressive. In this paper, we examine the nature of women's aggressive behaviour towards men in their intimate partner relationship in two different societies.

Methods The present study employs complementary methodologies to provide quantitative and qualitative data on intimate partner aggression. It applies the construct direct and indirect aggression to investigate aggressive behaviour in heterosexual intimate relationships in Ghana using the Direct Indirect Scales for Adult (DIAS-Adult), $(\mathrm{n}=1204)$, and by analysing ethnographic interviews and observations conducted over two years in Bosnian Muslims in Närpes, Finland, in order to have a holistic and culturally meaningful perspective on aggression.

Results Females were found to victimise and perpetrate aggressive acts more than males in Ghana. Findings on Bosnian Muslim women in Närpiö reveal the presence of direct verbal aggression and indirect aggression towards their intimate men partners. Survey and ethnographic findings within the two cultures converge in suggesting that women also employ aggression to deal with frustrations and conflict.

Conclusions Through changing times, women are becoming increasingly active in their "male-dominated" societies and are becoming much more independent and self-motivated. From the two study results, we glean that developmental efforts to empower women have an impact on their use of aggression in 
intimate relationships and there is a presence of male victimisation.

\section{SEX DIFFERENCES IN INTIMATE PARTNER AGGRESSION IN GHANA}

George Darko. Åbo Akademi University, Vaasa, Finland

10.1136/injuryprev-2016-042156.986

Background The United Nations identifies male-dominated Africa as one of the worst regions for a woman to live globally, in terms of intimate partner aggression (IPA). There have been efforts the past two decades, to empower women through education and employment. Previous research though has typically focused on males' physical aggression to understand the sex differences in IPA resulting in the lack of understanding of the nature of sex the differences in IPA in male-dominated Africa. This current study explored sex differences in IPA in forms of aggression typically used in intimate relationships in both males and females in Ghana with the DIAS-Adult instrument.

Methods 602 males and 602 females in heterosexual intimate relationship aged above 21 years in Ghana filled in a questionnaire measuring victimisation from and perpetration of aggressive behaviour in intimate partner relationships using the Direct Indirect Aggression Scales for Adults (DIAS-Adult, Österman \& Björkqvist, 2009). The age difference between males (mean age 44.8 yrs., SD 13.4) and females (mean age 43.4 yrs., SD 13.6) was not significant. The subscales measure victimisation from and perpetration of physical, socially manipulative aggression, nonverbal, cyber and economic aggression. The alpha scores for the 10 subscales were all above .68 .

Results Results show that females scored significantly higher than males on being perpetrators of physical, socially manipulative aggression, nonverbal and cyber aggression. Males scored significantly higher than females on being victimised by their partner of physical, socially manipulative aggression, nonverbal and cyber aggression.

Conclusions The findings suggest that developmental efforts to empower women might be enabling females become more independent, allowing them to redefine their roles in the society, however, this may also be having unintended negative effect on female aggression in intimate relationships.

\section{SRI LANKAN GENERAL PRACTITIONERS' (GPS') KNOWLEDGE, ATTITUDES, AND SKILLS ON GENDER- BASED VIOLENCE}

Achini Jayatilleke, Lakshmen Senanayake, Sumithra Tissera, Dileep Gamage, T Tiny Weerakkodi. Family Planning Association of Sri Lanka, Colombo, Sri Lanka

\subsection{6/injuryprev-2016-042156.987}

Background As family physicians, General Practitioners (GPs) have a high capacity to identify and assist the survivors of gender-based violence (GBV). However, in Sri Lanka, GPs are not trained to provide GBV services. This study aimed to assess Sri Lankan GPs' knowledge, attitudes and skills on GBV, in order to identify their training needs.

Methods We conducted a postal survey between $1^{\text {st }}$ June and $31^{\text {st }}$ July 2015 with all the registered full-time GPs in Sri Lanka $(\mathrm{n}=526)$. An anonymous self-administered structured questionnaires was used to assess GPs' knowledge, attitudes, responsibility, and self-reported practices on GBV. Out of the 526 GPs, 124 returned completed questionnaires. We analysed data using SPSS version 20 statistical software.

Results Of all the GPs included in the study $(\mathrm{n}=124), 70.5 \%$ were male, $80.2 \%$ were more than 45 years old, and $83.5 \%$ were practicing as GPs for more than 5 years. The mean score for GPs' GBV knowledge was 20.8\% (Standard Deviation $(\mathrm{SD})=5.52$ ). The mean score for attitudes on GBV was $60.35 \%(S D=15.13$ ), and for perceived responsibility to assist GBV survivors was $61.57 \%$ ( $S D=13.50)$. The mean score for the self-confidence to identify and manage GBV was $75.28 \%(\mathrm{SD}=20.50)$. When asked, $56.1 \%$ reported that they see a GBV survivor very rarely, and only $8.3 \%$ reported that they see a GBV survivor at least once a week; it is known that one in three Sri Lankan women experience GBV. Of all, $77.2 \%$ of the GPs believed that they should intervene to prevent GBV because it is a health issue, while only $56.1 \%$ believed that GBV is a human rights violation.

Conclusion GPs' have a high self-confidence to identify and assist GBV survivors. However, their knowledge on GBV is less. Possibly because of that, in actual practice, GPs rarely identify GBV. Although, several GPs identify GBV as a health problem, almost $45 \%$ of the GPs do not see GBV as a human rights violation. Improving GP's knowledge on GBV might improve their response for GBV.

\section{INTIMATE PARTNER VIOLENCE AND NETWORKING: WHAT ROLE FOR HEALTH SERVICES? STRATEGY IN COIMBRA}

${ }^{1}$ João Redondo, ${ }^{2}$ Anabela Fazendeiro, ${ }^{3}$ Teresa Bombas, ${ }^{4}$ Eduardo Castela, ${ }^{5}$ António Veiga, ${ }^{6}$ Filipa Pereira, ${ }^{7}$ Odete Mendes, ${ }^{8}$ Madalena Alarcão, ${ }^{9}$ António Monteiro, ${ }^{10}$ Henrique Armindo, ${ }^{11}$ Paula Garcia, ${ }^{12}$ Isabel Morais, ${ }^{13}$ Emilia Batista, ${ }^{14}$ Fátima Mota, ${ }^{15}$ Natália Cardoso, ${ }^{16,17}$ Vânia SarmentoRosário Lemos, ${ }^{6}$ Sara Rosado, ${ }^{1}$ Generosa Morais, ${ }^{1}$ Ana Correia, 'Dulce Carvalho, 'Lurdes Teixeira, 'Ana Dourado, 'Salomé Caldeira, ${ }^{1}$ António Jorge. ${ }^{1}$ Centre for Prevention and Treatment of Psychological Trauma (CPTTP), Department of Psychiatry, Coimbra University Hospital Centre (CHUC), Portugal; ${ }^{2}$ Child and Adolescent Psychiatry Service, CHUC, Portugal; ${ }^{3}$ Obstetrics Service A, CHUC, Portugal; ${ }^{4}$ Telemedicine, CHUC, Portugal; ${ }^{5}$ Emergency Department,CHUC, Portugal; ${ }^{6}$ National Institute of Medical Emergency (INEM), Portugal; ${ }^{7}$ Primary Health Care, Regional Health Administration of the Centre Region (ARSC), Portugal; ${ }^{8}$ Faculty of Psychology and Educational Sciences of the University of Coimbra, Portugal; ${ }^{9}$ Public Security Police (PSP) of Coimbra, Portugal; ${ }^{10}$ National Guard (GNR), Coimbra, Portugal ${ }^{11}$ Department for Investigation and Penal Action (DIAP), Portugal; ${ }^{12}$ Coimbra Group of Schools West, Portugal; ${ }^{13}$ District Centre of Solidarity and Social Security of the District of Coimbra, Portugal; ${ }^{14}$ Bissaya Barreto Foundation (FBB), Portugal; ${ }^{15}$ Office of Victim Support Coimbra, APAV, Portugal; ${ }^{16}$ Commission for the Protection of Children and Youth of Coimbra (CPCJ), Portuga; ${ }^{17}$ Center Delegation of the National Institute of Legal Medicine and Forensic Sciences, Portugal

\subsection{6/injuryprev-2016-042156.988}

Background Violence by intimate partners (IPV) can be prevented and its impact reduced. This calls for to deal with violence from a public health perspective, according the ecological model, associated to a multidisciplinary and multisectoral networking approach. In Coimbra various sectors are working together from 2000 , in tackling the problem of IPV. Health sector is an active and valuable ally in the global response to violence and brings a variety of advantages and assets to this work, from primary to terciary prevention, including programs for victims and perpetrators.

Description of the problem IPV is a serious problem that occurs in all countries, among heterosexual or same-sex couples. The consequences are profound, extending beyond the health and 